\title{
New copolymer of acrylamide with allyl methacrylate and its capacity for the removal of azo dyes
}

\author{
Yeliz Yildirim', Habibe Yilmaz², Guliz Ak ${ }^{2}$ and Senay Hamarat Sanlier ${ }^{2}$ \\ 'Department of Chemistry, Faculty of Science, Ege University, Bornova, Izmir, Turkey \\ ${ }^{2}$ Department of Biochemistry, Faculty of Science, Ege University, Bornova, Izmir, Turkey \\ *yeliz.yildirim@ege.edu.tr
}

\begin{abstract}
The copolymerization reactions of Acrylamide (AA) with the different mole ratios of allyl methacrylate (AMA) such as 25/75, 50/50 and 75/25 were studied by radical polymerization under argon atmosphere using 2,2'-Azobis (isobutyronitri1e) (AIBN) as initiator. The copolymers were characterized with Fourier transform infrared spectroscopy (FTIR) and thermogravimetric analysis (TG). FTIR spectra showed that the $\mathrm{C}=\mathrm{O}, \mathrm{C}-\mathrm{N}$ and $\mathrm{N}-\mathrm{H}$ groups in copolymers remained during the copolymerization. It is concluded from the thermograms that Poly(AA-co-AMA) copolymers which contained different ratios of monomer and comonomer exhibit similar thermal behavior. Adsorption capacity, kinetic and isotherm studies of Direct Brown 2 onto the copolymers have been evaluated. Different factors such as the monomer ratio, $\mathrm{pH}$, initial dye concentration, copolymer dosage and contact time affecting the removal process were studied. It was found that the adsorption process agreed with the Freundlich and Dubinin-Raduskevich model and the adsorption of Direct Brown 2 depended on the acrylamide content and $\mathrm{pH}$ of the solution. The standard Gibb's free energy was determined as $-14.7 \mathrm{~kJ} / \mathrm{mol}$, which means that adsorption occurred spontaneously and the process is feasible. Increasing the acrylamide content led to increased adsorption of Direct Brown 2 on the copolymer. Moreover, adsorption kinetic studies showed that the adsorption followed a pseudo-second-order kinetic model, indicating that the chemical adsorption was the rate-limiting step. These results show that Poly(AA-co-AMA) can be used as adsorbent for water pollutants such as Direct Brown 2 and has potential applications in related industrial and environmental areas.
\end{abstract}

Keywords: acrylamide, allyl methacrylate, azo dye, adsorption isotherm, adsorption kinetics.

\section{Introduction}

Dyes from waste effluents are widely generated in several industries such as textile, leather, paper, pharmaceutical, plastic, and food. The chemical oxidation, foam flotation, electrolysis, biodegradation, adsorption, chemical coagulation and photocatalysis are known as the most effective methods for removal of dye from industrial water of dyes. Adsorption is the effective and simple method to remove pollutants from wastewater. Several polymers and copolymers such as poly(N-vinylpyrrolidone-co-methacrylic acid), polystyrene-graft-poly(N,N-dimethylamino-2-ethyl methacrylate), aniline-formaldehyde polymer and so on as adsorbents were studied for their ability to remove metals or dyes ${ }^{[1-3]}$.

In recent years, many researchers have worked for development of new adsorbents having superior properties such as high adsorption capacity, fast adsorption rate, and mechanical strength. The several polymers having different functional groups have been also investigated in the preceding literature for this purpose. AA monomer has the amine and vinyl group. Because of their higher reactivities, bifunctional monomers containing two reactive groups can be used for the preparation of functional (co)polymers. In the related literature, AA monomer was copolymerized with different functional monomers in order to obtain useful synthetic adsorbents for dye removal of water. Solpan et al have studied the radiation-induced copolymerization of acrylamide and acrylic acid to uptake of some cationic dyes such as

Safranine and Magenta ${ }^{[4]}$. Poly(acrylamide-co-ethylene glycol dimethacrylate) was synthesized to remove catechins and caffeine by $\mathrm{Lu}$ et al. ${ }^{[5]}$ There are also a lot of studies about poly(acryamide) modification. Composite hydrogels based on polyacrylamide and chitosan were prepared to absorb of the anionic or cationic dyes ${ }^{[6]}$. Multiwalled carbon nanotubes have been grafted with poly(acrylamide) and with poly(N,N-dimethylacrylamide) to compare their adsorption capacities ${ }^{[7]}$. The cross linked poly (acrylic acid-co-acrylamide)/attapulgite (Poly(AA-co-AM)/ATP) composite to remove Methyl Violet (MV) cationic dye from aqueous solution have been reported by Wang et al. ${ }^{[8]}$. The studies have shown that acrylamide exhibits good adsorption capacity for the compounds since its amino and carbonyl groups may act as chelating sites.

Azo colorants have a coloring effect containing one or two azo groups ( $\mathrm{N}=\mathrm{N}$ double bonds) in their chemical structures. They are synthesized by coupling diazotized aromatic amines with other aromatic compounds. They are the largest group of synthetic colorants (60-70\%) and can be used for the coloration of textile fibers, plastics, leather, cosmetics etc. Reductive cleavage of the azo linkage under anaerobic conditions has promoted concerns about the release of known carcinogens such as benzidine. These aromatic amines are biorefractory and highly toxic because they can react easily in the blood to convert hemoglobine into methahemoglobine and preventing oxygen uptake. It 
is necessary to de-pollution of these azo dyes in order to avoid their dangerous environmental accumulation ${ }^{[9]}$. In order to remove these azo dyes from waste water, there are numbers of studies using polymers, hydrogels, natural polymer grafted synthetic polymers.

The object of the current study was to improve the adsorption capabilities of acrylamide for azo dyes. In this study, we attempt to prepare poly(acrylamide-co-allyl methacrylate) (Poly(AA-co-AMA) with different mole ratios by radicalic polymerization for removal of azo dyes from aqueous solution. The adsorption properties in azo dyes solution such as Direct Brown 2 of synthesized copolymers were investigated.

\section{Experimental}

\subsection{Materials}

The Acrylamide, AA (stated purity $98 \%$ ) was purchased from Fluka, Allyl Methacrylate, AMA, (stated purity 98\%) were purchased from Merck. The chemicals were used without any further purification.

\subsection{Instrumentation}

The FTIR (Fourier Transform Infrared Spectroscopy) spectra of the copolymers were obtained by using Perkin Elmer Spectrum 100 FT-IR Spectrometer by KBr pellet technique.

TG measurements of copolymers were obtained on Perkin-Elmer Diamond TA/TGA from 30 to $600^{\circ} \mathrm{C}$ at the $10^{\circ} \mathrm{C} \mathrm{m^{-1 }}$ heating rate under constant flow of $100 \mathrm{~mL} / \mathrm{min}$ of nitrogen atmosphere. The sample weights for all the experiments were taken in the range of $8-10 \mathrm{mg}$.

Spectrophotometrical measurements of Direct Brown 2 were obtained on UV/VIS Perkin-Elmer Spectrophotometer at $409 \mathrm{~nm}$.

\subsection{Preparation of Poly(AA-co-AMA) copolymer in different $A A / A M A$ ratio}

Three different mole compositions of AA and AMA monomers such as 25/75, 50/50, and 75/25 and 0.0001 mmole of AIBN were placed into a pyrex flask. The polymerization was carried out at $60^{\circ} \mathrm{C}$ for 1 hour under argon atmosphere. At the end of the reaction period, the copolymers of Poly(AA-co-AMA) were washed with methanol. The copolymers were dried in vacuum oven at $50^{\circ} \mathrm{C}$. The dried copolymer samples were then analyzed by using FTIR and TG.

\subsection{Adsorption studies}

\subsubsection{Determination the monomer ratio for dye removal}

In order to determine the effect of monomer rate of copolymer for the most efficient dye removal, three different copolymers synthesized with different monomer ratios. These monomer ratios are $25 \% \mathrm{AA}$ and $75 \% \mathrm{AMA}(\mathrm{K} 1), 50 \% \mathrm{AA}$ and $50 \% \mathrm{AMA}(\mathrm{K} 2)$, and $75 \% \mathrm{AA}$ and $25 \% \mathrm{AMA}(\mathrm{K} 3) .50 \mathrm{mg}$ different copolymers (K1, K2 and K3) incubated with $2 \mathrm{~mL}$ $(1 \mathrm{mg} / \mathrm{mL})$ dye solution for 2 hours in room temperature under constant shaking $(240 \mathrm{rpm})$. At the end of the incubation period, samples were centrifugated at $3000 \mathrm{rpm}$ for 10 minutes in order to precipitate the copolymer. The dye amount of the upper phase was determined spectrophotometrically (409 nm). Dye removal efficiency was calculated using the following Equation $1^{[10]}$.

$\%$ Dye removal $=\frac{\text { Initial dye amount }(\mathrm{mg})-\text { Remaining dye amount }(\mathrm{mg})}{\text { Initial dye amount }(\mathrm{mg})} \times 100$

\subsubsection{The effect of $\mathrm{pH}$ on dye removal}

In order to investigate the effect of $\mathrm{pH}$ on dye removal of the copolymer, different buffer solutions prepared that $\mathrm{pH}$ ranges from $2-10(\mathrm{pH} 2$ glycine/ $\mathrm{HCl}$ buffer, $\mathrm{pH}$ 3-5 sodium acetate buffer, $\mathrm{pH}$ 6-8 phosphate buffer, $\mathrm{pH}$ 9-10 glycine/ $\mathrm{NaOH}$ buffer). Concentration of the buffer solutions were chosen as $10 \mathrm{mM}$. $1 \mathrm{mg} / \mathrm{mL}$ dye solutions was prepared by using different $\mathrm{pH}$ buffers. $2 \mathrm{ml}$ dye solutions with different $\mathrm{pH}$ added to $50 \mathrm{mg}$ of copolymer and incubation was performed at room temperature for 2 hours. At the end of the incubation period, samples were centrifugated at $3000 \mathrm{rpm}$ for 10 minutes in order to precipitate the copolymer and the dye amount of the upper phase were determined spectrophotometrically $(409 \mathrm{~nm})^{[11]}$.

\subsubsection{The effect of initial dye concentration on dye removal efficiency}

In order to determine the effect of dye concentration on dye removal yield, dye solutions prepared using $10 \mathrm{mM}$ acetate buffer ( $\mathrm{pH} 3.0$ ) with varying concentrations from 0.2 to $0.01 \mathrm{mg} / \mathrm{mL}$. Dye solutions with different concentrations were added onto copolymer and allowed to incubation for 2 hours at room temperature under constant shaking (240 rpm). At the end of the incubation period, samples were centrifugated at $3000 \mathrm{rpm}$ for 10 minutes in order to precipitate the copolymer and the dye amount of the upper phase were determined spectrophotometrically $(409 \mathrm{~nm})^{[12]}$.

\subsubsection{Effect of copolymer dosage}

In order to investigate the effect of varying the amount of copolymer, 5-400 mg copolymer weighted and $2 \mathrm{~mL}$ $\mathrm{pH} 3.0,0.01 \mathrm{mg} / \mathrm{mL}$ dye solutions added. It was allowed to incubate at room temperature for 2 hours. At the end of the incubation period, samples were centrifugated at $3000 \mathrm{rpm}$ for 10 minutes in order to precipitate the copolymer and the dye amount of the upper phase were determined spectrophotometrically $(409 \mathrm{~nm})^{[12]}$.

\subsubsection{Effect of contact time on dye removal}

The batch system was established under optimum conditions and the removal of Direct Brown 2 was examined depending on time. For this purpose, $200 \mathrm{mg}$ copolymer was treated with $50 \mathrm{~mL}$ ( $\mathrm{pH} 3.0,0.01 \mathrm{mg} / \mathrm{mL}$ concentration) dye solution. At pre-determined time intervals (5-120 minutes), the upper phase is collected to determine the amount of dye in the upper phase and dye removal time was estimated spectrophotometrically ${ }^{[11]}$.

\subsubsection{Direct Brown 2 desorption from copolymer}

Batch system was set by using optimum copolymer amount and dye solution and system was incubated for 45 minutes. At the end of the incubation, $\mathrm{pH}$ of equilibrium 
was pulled alkaline region from acidic region (3-10) and desorption behavior was examined under changing $\mathrm{pH}^{[12]}$.

\subsubsection{Adsorption Isotherms and thermodinamic modelling}

The experiments performed to observe the effect of concentration at constant $\mathrm{pH}$ and temperature. Copolymer was taken in tubes containing $2 \mathrm{~mL}$ each of different Direct Brown 2 concentrations. These tubes then constantly shaken at $25^{\circ} \mathrm{C}$ for 45 minutes. Then, samples centrifugated at $3,000 \mathrm{rpm}$ and unadsorbed dye amount calculated. $\Delta \mathrm{G}$ of the adsorption calculated by using Langmuir constant $\mathrm{Q}_{0}$. For all isotherm models dye concentration varied from $10-200 \mu \mathrm{g} / \mathrm{mL}$.

Adsorption isotherms of dye were studied. Dubinin-Radushkevich, Freundlich and Langmuir isotherms applied and constants calculated.

\subsubsection{Adsorption kinetics}

The experiment performed to observe the effect of time at constant $\mathrm{pH}$, concentration and temperature. $200 \mathrm{mg}$ copolymer was taken in a flask containing $50 \mathrm{~mL}$ dye $(0.01 \mathrm{mg} / \mathrm{mL})$. The flask was constantly shaken at $25^{\circ} \mathrm{C}$ for 2 hours. Then, at predetermined time intervals $2 \mathrm{~mL}$ sample was taken from equilibrium and measured spectrophotometrically. After measurement the sample was poured back to the equilibrium. Adsorption change with time was estimated, kinetic models applied and kinetic constants were calculated.

\section{Results and Discussion}

In this paper, the copolymers which contain different mole ratios $(75 / 25,50 / 50,25 / 75$ mmoles $)$ of the $\mathrm{AA}$ and AMA synthesized at the $60^{\circ} \mathrm{C}$ in the 1 hour under the argon atmosphere. Table 1 is demonstrated copolymerization yield and AA/AMA ratio. The copolymerization yield is given as the ratio of the weight of monomer to the weight of product. The proposed possible copolymerization reaction of the monomers is shown in Figure 1.

The FTIR spectra of Poly(AA-co-AMA) in three different compositions (AMA/AA mole ratios, 25/75, 50/50, and 75/25) are shown in Figures $2 \mathrm{a}, \mathrm{b}$ and $\mathrm{c}$. The peak assignment for the FTIR spectrum of the Poly(AA-co-AMA) is as follows: $\mathrm{C}-\mathrm{H}$ in $\mathrm{CH}_{3}$ and $\mathrm{C}-\mathrm{H}$ in $\mathrm{CH}_{2}$ between $2900-3100 \mathrm{~cm}^{-1}, \mathrm{CH}_{2}$ at $1457 \mathrm{~cm}^{-1} ; \mathrm{CH}_{3}$ at $1389 \mathrm{~cm}^{-1} ; \mathrm{C}=\mathrm{C}$ in allyl group around $1650 \mathrm{~cm}^{-1} ; \mathrm{CH}=\mathrm{C}$ for allyl group around 980 and $929 \mathrm{~cm}^{-1}$. The absorption peak corresponding to allylic double bond at 980 and $929 \mathrm{~cm}^{-1}$ still exists even with a reduced intensity

Table 1. The copolymerization yields of the Poly(AA-co-AMA) with different AA/AMA ratio.

\begin{tabular}{cc}
\hline AA/AMA mole ratio & Polymerization yields (\%) \\
\hline $75 / 25$ & 80 \\
$50 / 50$ & 83 \\
$25 / 75$ & 81 \\
\hline
\end{tabular}<smiles>C=CCOC(=[OH+])C(=C)C</smiles>

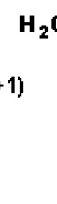

Acrylamide $(A A)$

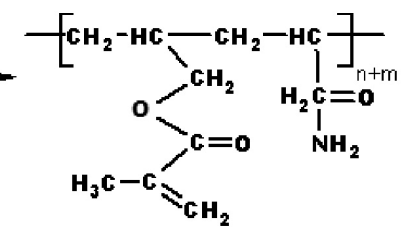

Poly(AA-co-AMA)

$m=$ the repeated unit numbers of AA

$n=$ the repeated unit numbers of AMA

Figure 1. The proposed possible copolymerization reactions of the AA and AMA monomers.
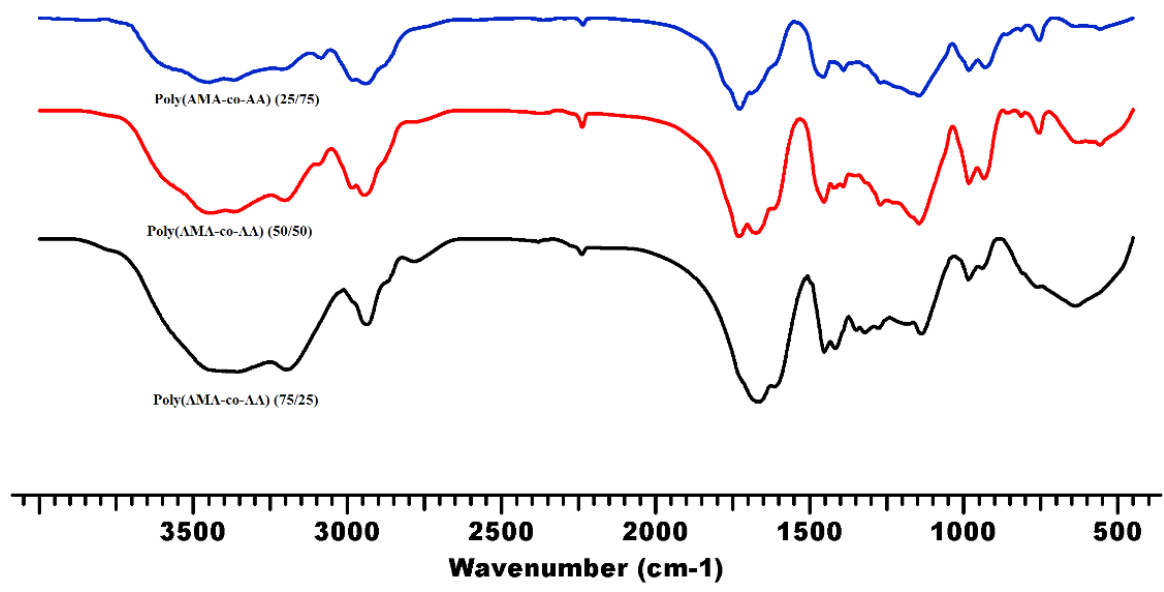

Figure 2. The FTIR spectrum of the Poly(AA-co-AMA) with different AA/AMA ratio. 
than that in the monomer spectrum. But the absorption peak of the vinyl group at $800 \mathrm{~cm}^{-1}$ vanishes completely in copolymer spectrum which indicates that the copolymer does not contain any vinyl group. The FTIR absorption bands for $\mathrm{C}=\mathrm{O}$ bond of the copolymers take place around $1720 \mathrm{~cm}^{-1}$ and C-N band appear between 2230-2240 $\mathrm{cm}^{-1}$. As seen in Figure 2, the much broader absorption peaks around 3400 and $3190 \mathrm{~cm}^{-1}$ due to the asymmetricand symmetric $\mathrm{N}-\mathrm{H}$ stretching, respectively.

\subsection{Thermogravimetric analysis of the copolymers}

Thermogravimetric analysis (TG) was used to investigate the thermal stability. The TG thermograms of the Poly(AA-co-AMA) in three different compositions (AMA/AA mole ratios, 25/75, 50/50, and 75/25) are shown in Figure $3 \mathrm{a}$. To determine the thermal stability of the copolymers, the temperaturefor the maximum weight loss $\left(\mathrm{T}_{\max }\right)$ and the temperature for half-life $\left(\mathrm{T}_{1 / 2}\right)$ were found directly from its dynamic thermograms given in Figure $3 \mathrm{~b}$.

It is shown in Figure 3 that there is only one decomposition stage for the $\mathrm{K} 1$ copolymer. The temperature for maximum weight loss of the copolymer is $\mathrm{T}_{\max } 424^{\circ} \mathrm{C}$ and $\mathrm{T}_{1 / 2} 413^{\circ} \mathrm{C}$. On the other hand, there are two decomposition stages for those of 50/50 and 75/25 mole ratio of the copolymers. Very weak peaks with $\mathrm{T}_{\text {max }}=305^{\circ} \mathrm{C}$ and $\mathrm{T}_{\text {max }}=310^{\circ} \mathrm{C}$ are observed in the DTG curves of $\mathrm{K} 2$ and $\mathrm{K} 3$ copolymers, respectively over the temperature range 200 to $330^{\circ} \mathrm{C}$ with the weight losses of $9 \%$ for $\mathrm{K} 2$ and $13 \%$ for K 3 copolymers. These very

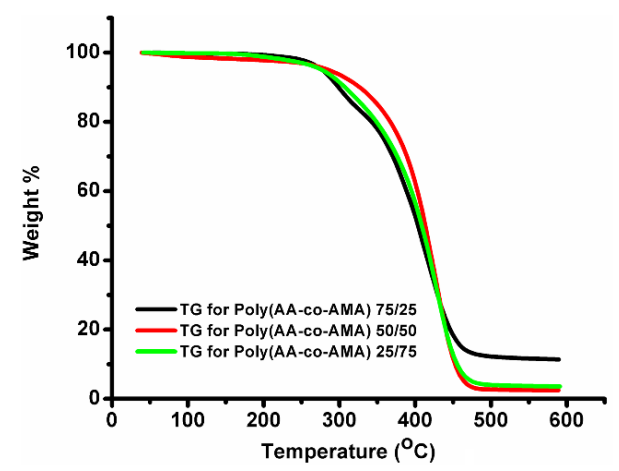

(a)

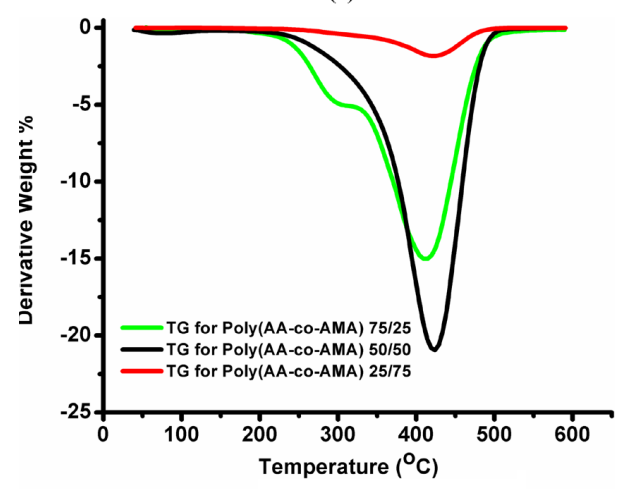

(b)

Figure 3. a) The TG thermograms of the Poly(AA-co-AMA) with different AA/AMA ratio. b) The DTG thermograms of the Poly(AA-co-AMA) with different AA/AMA ratio. weak peaks in the DTG curves of $\mathrm{K} 2$ and $\mathrm{K} 3$ copolymers may be due to branching structure in the copolymers from the tip of AMA monomer. The $\mathrm{T}_{\max }$ and $\mathrm{T}_{1 / 2}$ are 421 and $409^{\circ} \mathrm{C}$ for $\mathrm{K} 2$, and 412 and $404^{\circ} \mathrm{C}$ for $\mathrm{K} 3$ copolymers. The $\mathrm{K} 3$ copolymer also gives $10 \%$ residue over $600^{\circ} \mathrm{C}$. The TG results show that thermal decomposition temperatures increase with rising AA content. $\mathrm{T}_{\text {max }}$ for Poly(acrylamide) (PAA) is $396^{\circ} \mathrm{C}$ and $\mathrm{T}_{1 / 2}$ is $418^{\circ} \mathrm{C}$. PAA gives $25 \%$ residue at $600^{\circ} \mathrm{C}^{[13]} \cdot \mathrm{T}_{\max }$ and $\mathrm{T}_{1 / 2}$ are given as $409^{\circ} \mathrm{C}$ and $400^{\circ} \mathrm{C}$ for Poly(allylmethacrylate) (PAMA) homopolymer in the literature, respectively ${ }^{[14,15]}$. Consequently, it is understood that the thermal stability and the temperature for maximum weight loss of Poly(AA-co-AMA) copolymers are between those of PAA and PAMA homopolymers indicating that thermal stabilities of PAMA, PAA and Poly(AA-co-AMA) are found to be rather similar.

\subsection{Determination the monomer ratio for dye removal}

The result of the attempt to dye removal with $\mathrm{K} 1$ copolymer, copolymer dissolution in dye solution was observed and is not able to remove any dye from equilibrium. This dissolutions was observed based on the $-\mathrm{NH}_{2}$ groups of AA monomer. Because of this $-\mathrm{NH}_{2}$ residues copolymer gains hydrophilic character and becomes soluble in water. Copolymer K2 is not dissolved in dye solution but yet it was not able to remove any dye from equilibrum. The copolymer K2 may become more insoluble due to the decreased number of $-\mathrm{NH}_{2}$ residues. Therefore the copolymer did not dissolved in equilibrium. However, it still cannot adsorp the dye because dye cannot compete with water. But the experiment with copolymer K3 gave $50 \%$ percent dye removal yield. In consequence of dye removal rate is higher of $\mathrm{K} 3$ compared with other copolymers under unoptimized conditions, it is decided to continue with copolymer which contains $25 \%$ allyl methacrylate and $75 \%$ acrylamide monomers for dye removal study.

\subsection{The effect of $\mathrm{pH}$ on dye removal}

In order to determine the optimum $\mathrm{pH}$ where dye can be maximum adsorbed, dye removal yield was measured under varying $\mathrm{pHs}$. Dye is not soluble at $\mathrm{pH} 2$ which is why the $\mathrm{pH}$ range chosen as 3 to 10 . The most dye removal was observed at $\mathrm{pH} 3$ with $100 \%$ and as seen in Figure 4 the yield was decreased with increasing $\mathrm{pH}^{[16]}$.

It is thought that at $\mathrm{pH} 3$ carboxyl and sulfonyl groups of dye is negatively charged and the copolymer is positively charged, consequently, dye removal yield is higher compared with other pHs. The carboxyl and sulfonyl groups of dye lose their negative charge with increasing $\mathrm{pH}$. On the other hand, the copolymer is positively charged at this $\mathrm{pH}$ due to its $-\mathrm{NH}_{2}$ residues. The negative charge of dye and positive charge of copolymer's AA monomer promoted the adsorption process. P. Senthil Kumar and co-workers removed Congo Red dye by using cashew nut shell. In their study, the adsorbate was an anionic dye and the adsorbent had positively charged character. The adsorption yield of Congo Red was decreased with increasing $\mathrm{pH}$ as in our study. Their finding is compatible with our finding ${ }^{[17]}$. 


\subsection{The effect of initial dye concentration on dye removal efficiency}

It is aimed to estimate the dye concentration effect on dye removal yield. For this purpose, the dye concentration range chosen as 0.01 to $0.2 \mathrm{mg} / \mathrm{mL}$. An adsorbent has limited binding site for adsorbate molecules which become saturated at a certain concentration. Consequently, with increasing dye concentration dye removal yield is decreases. As can be seen in Figure 5 copolymer is saturated with increasing dye concentration and it results with a decrease in dye removal yield. Chowdhury S. and coworkers removed Basic Green 4 by using Ananascomosus leaf powder. They used initial dye concentration range as $0.02 \mathrm{mg} / \mathrm{mL}$ to $0.1 \mathrm{mg} / \mathrm{mL}$ which is 2 fold lower in our study. They found the similar results as in our study. It seemed that our results are compatible with their results ${ }^{[18]}$.

\subsection{Effect of copolymer dosage}

Adsorbent dosage is an important parameter which influences the sorption capacity of an adsorbent. Figure 6 shows the adsorption profile of Direct Brown 2 versus different copolymer concentration in the range of 0.005-0.4 g. It can be seen that the adsorption increased with increasing adsorbent dosage and after $0.2 \mathrm{~g}$ adsorbent dosage there was no significant change in dye removal yield. The positive correlation between copolymer dosage and dye removal can be explained with increased adsorbent surface area and availability of more binding sites.

\subsection{Effect of contact time on dye removal}

The uptake of Direct Brown 2 on copolymer was rapidly occurred in first 30 minutes and reached $70 \%$ sorption yield as seen in Figure 7. This increase was continued until 45 minutes and $93 \%$ of dye adsorbed at that time. After 45 minutes adsorption slowed down and reached to the equilibrium with a $100 \%$ dye removal yield. It is thought that the optimum contact time is 45 minutes because the sorption after that time was really slower also no significant dye removal yield occurred. Mittal A. used fen heathers to remove Brilliant Blue FCF. In his study, sorption comes to equilibrium after 200 minutes ${ }^{[19]}$. However we reached equilibrium after 45 minutes which indicates that our study showed better removal time compared with Mittal A.'s study. The reason for this time shift may be due to the positive charge of copolymer which is accelerates the rate of adsorption.

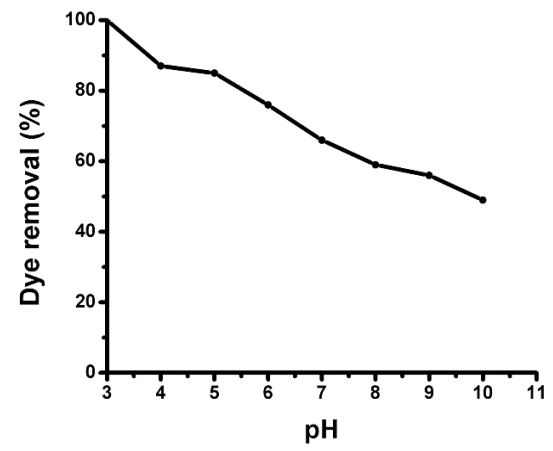

Figure 4. pH effect on dye removal.
The positive charge of copolymer and negative charge of dye drives the adsorption in a chemical nature which will be discussed in further sections.

\subsection{Direct Brown 2 desorption from copolymer}

Desorption is an important parameter for re-usage of adsorbents in industry. For this reason it is important to establish desorption yield. As seen in Figure 8, desorption increased with increased $\mathrm{pH}$. Owing to the increasing $\mathrm{pH}$, carboxyl and sulfonyl groups of dye protonated and lost their negative charge and it is similar for the copolymer. Ionic interactions between anionic dye and positively charged copolymer were broken with increasing $\mathrm{pH}$. In our study, copolymer released $63 \%$ of adsorbed dye in alkaline conditions means that copolymer has potential for re-usage.

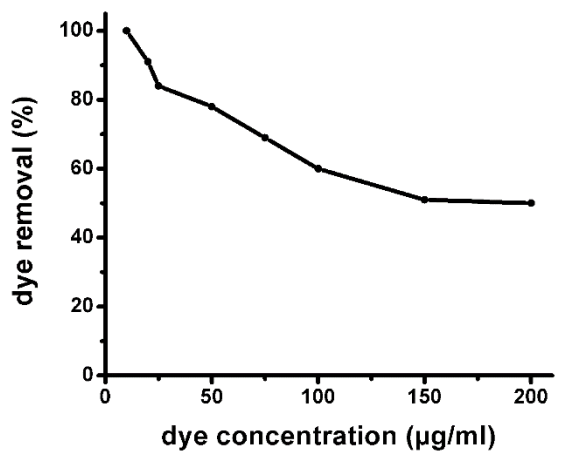

Figure 5. Initial dye concentration effect on adsorption yield.

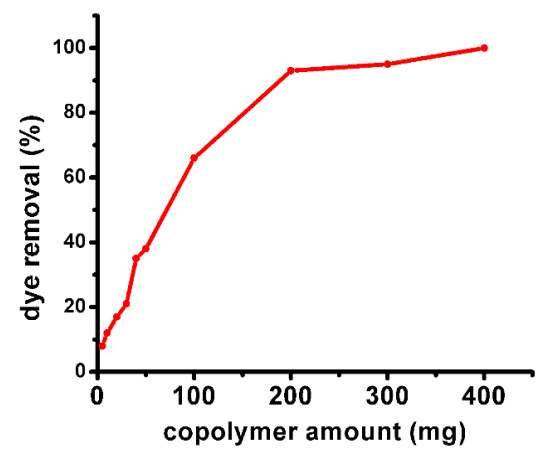

Figure 6. Dye adsorption with varying copolymer amounts.

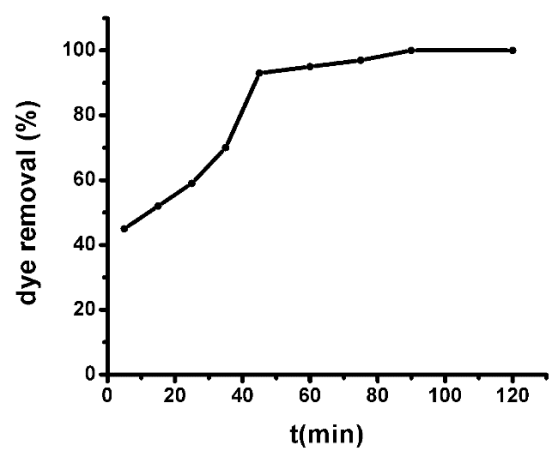

Figure 7. Contact time effect on adsorption removal yield. 


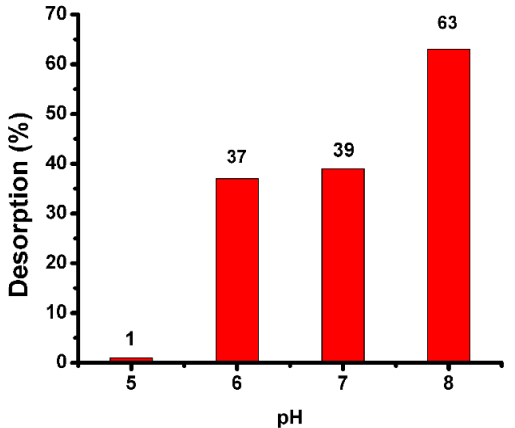

Figure 8. Desorption yield in different $\mathrm{pH}$ values.

\subsection{Adsorption isotherms and thermodinamic modelling}

Adsorption process can not be explained with just one adsorption model. Therefore, a few adsorption model should be applied for an equilibrium. Due to this necessity we studied Langmuir, Freundlich and Dubinin-Raduskevich isotherms, and calculated the related constants. Isotherm models were given below.

Langmiur adsorption isotherm explaines the monolayer coverage of the sorbate on a sorbent surface at a constant temperature. The assumption is that the forces exerted by chemically unsaturated surface atoms do not extend further than diameter of one sorbed molecule ${ }^{[20]}$. The linear Langmuir curve's equations:

$$
\frac{C_{e q}}{q_{e q}}=\frac{1}{Q_{b} x b}+\frac{C_{e q}}{Q_{0}}
$$

$\mathrm{C}_{\mathrm{eq}}$ is the concentration of dye solution $(\mathrm{mg} / \mathrm{L})$ at equilibrium, $\mathrm{Q}_{\mathrm{eq}}$ is the amount of dye adsorbed per unit weight of copolymer $(\mathrm{mg} / \mathrm{g}) . \mathrm{Q}_{0}$ gives the theoretical monolayer adsorption capacity ( $\mathrm{mol} / \mathrm{g}$ ) and $\mathrm{b}$ is the Langmiur constant which is related with the energy of adsorption $(\mathrm{L} / \mathrm{mol})$. A plot of $\mathrm{C}_{\mathrm{eq}} / \mathrm{Q}_{\mathrm{eq}}$ versus $\mathrm{C}_{\mathrm{eq}}$ yields a straight line with slope $1 / \mathrm{Q}_{0}$ and intercept $\mathrm{b}$.

To identify the favour ability of the adsorption, dimensionless constant seperation factor $\mathrm{R}$ is expressed as:

$$
\boldsymbol{R}_{L}=\frac{1}{1+\left(\boldsymbol{b} \times \boldsymbol{C}_{0}\right)}
$$

$R_{L}$ value indicates the state of adsorption as follows; $R_{L}>1$, unfavourable; $\mathrm{R}_{\mathrm{L}}=1$, linear; $0<\mathrm{R}_{\mathrm{L}}<1$, favourable; $\mathrm{R}_{\mathrm{L}}=0$, irreversible ${ }^{[21]}$.

In the present study, the theoretical monolayer adsorption capacity was found $7 \mathrm{mg} / \mathrm{g}$ and Langmiur constant was found $0.006 \mathrm{~L} / \mathrm{mg}$. $\mathrm{R}_{\mathrm{L}}$ value was 1 which means the adsorption of dye is linear. However Langmuir isotherm model is not sufficient to explain adsorption of equilibrium.

The changes in the standard Gibb's free energy were calculated using Langmuir isotherm constant $b$. The equation was shown below ${ }^{[21]}$ :

$$
\Delta G=-R T \ln b
$$

The negative standard Gibb's free energy values indicate the feasibility of the process and its spontaneous nature. The standard Gibb's free energy determined as $-12.7 \mathrm{~kJ} / \mathrm{mol}$. This value represents the adsorption occured spontaneously and process is feasible.

The Freundlich isotherm is an empirical equation based on a heterogenous surface. A linear form of the Freundlich expression will yield the constant $\mathrm{K}_{\mathrm{F}}$ and $\mathrm{n}$.

$$
\ln \boldsymbol{q}_{\boldsymbol{e q}}=\ln K F+\left(\frac{1}{n}\right) x \ln \boldsymbol{C}_{\boldsymbol{e q}}
$$

Therefore, a plot of $\operatorname{lnq}_{\mathrm{eq}}$ versus $\operatorname{lnC}_{\mathrm{e}}$ enables the constant $\mathrm{K}_{\mathrm{F}}$ and exponent $\mathrm{n}$ can be determined. $\mathrm{K}_{\mathrm{F}}$ can be defined as adsorption of distribution coefficient and represents the quantity of dye adsorbed with copolymer for an equilibrium concentration. The slope $1 / \mathrm{n}$, ranging between 0 and 1 is a measure of adsorpton intensity of surface heterogenity, becoming more heterogeneous as its value gets closer to the zero. If the adsorption intensity, $\mathrm{n}$ is less than 1 , it indicates that adsorption intensity is good over the entire range of concentration studied, but if the $\mathrm{n}$ value is more than 1 , it means that adsorption intensity is favourable at high concentration but much less at lower concentration ${ }^{[22]}$.

In our work, $\mathrm{K}_{\mathrm{F}}, \mathrm{n}$ and $1 / \mathrm{n}$ values determined as $0.013 \mathrm{~mol}^{1-1 / n} \mathrm{~L}^{1 / \mathrm{n}} \mathrm{g}^{-1}, 1.7$ and 0.6 , respectively. If the value $\mathrm{n}$ is more than 1 it means that the adsorption intensity is good at high concentrations and the value $1 / \mathrm{n}$ indicates that the surface of copolymer is more likely to be heterogenous. As can be seen from the results, $n$ value is more than 1 which means adsorption intensity is favourable at high concentrations for Direct Brown 2. $1 / \mathrm{n}$ value is between 1 and 0 . This value also indicates that the surface of adsorbant is heterogenous. Both constants correlates with adsorption nature. Moreover, based on this data we can assume that synthesized copolymer can be used to remove azo dyes from equilibrium even at high concentrations.

The Dubinin-Raduskevich isotherm does not assume a homogenous surface or constant sorption potential. The linear Dubinin-Raduskevich equation is,

$$
\ln q_{e}=\ln q_{m}-\beta \mathcal{E}^{2}
$$

Where $\mathrm{q}_{e}$ is the amount of dye adsorbed at equilibrium, $\beta$ is a constant related to the adsorption energy, $\mathrm{q}_{\mathrm{m}}$ is the theoritical saturation capacity, $\varepsilon$ is the Polanyi potential, that is equal to $\operatorname{RT}\left(1+1 / \mathrm{C}_{\mathrm{e}}\right)$. The slope of the plot of $\ln$ $\mathrm{q}_{\mathrm{e}}$ versus $\varepsilon^{2}$ gives $\beta\left(\mathrm{mol}^{2} / \mathrm{kJ}^{2}\right)$ and the intercept yields the sorption capacity, $\mathrm{q}_{\mathrm{m}}(\mathrm{mol} / \mathrm{g})^{[23]}$. The sorption free energy could be further calculated as follows;

$$
E=-(2 \boldsymbol{\beta})^{-1 / 2}
$$

The $\mathrm{E}$ value can be used for estimating the type of adsorption process. Two main types of adsorption may occur: physical and chemical adsorption. In physical adsorption equilibrium is usually rapidly attained and easily reversible, because the energy requirements are small (usually no more than $4.2 \mathrm{~kJ} / \mathrm{mol}$ ). The chemical adsorption is specific and involves forces which are much stronger than those in physical adsorption. So the sorption energy for chemical adsorption 
should be between 8 and $16 \mathrm{~kJ} / \mathrm{mol}$ which is also indicates that the adsorption follows ion-exchange mechanism ${ }^{[24]}$.

Obtained results revealed that theoritical saturation capacity is $13.4 \mathrm{mg} / \mathrm{g}$ and $\beta$ is -0.0023 . The value E calculated as $14.7 \mathrm{~kJ} / \mathrm{mol}$ which is between 8 and $16 \mathrm{~kJ} / \mathrm{mol}$. The result shows the adsorption was chemically occured with ion-exchange mechanism. Our copolymer has $-\mathrm{NH}_{2}$ residue which is positively charged at $\mathrm{pH} 3$ and carboxyl and sulfonyl groups of Direct Brown 2 is negatively charged. As a result, it is inevitable that the adsorption occurred in a chemical nature. This type of adsorption for dye removal studies is feasible because dye removal can be performed in a more controlled manner. Also, the calculated Gibbs free energy from Langmuir constant supports the result of Dubinin-Raduskevich isotherm model. Both results showed that synthesized copolymer is efficient to remove Direct Brown 2.

Each isotherm model can not be used to explain the related adsorption nature due to the properties of adsorbant material. Therefore, according to the correlation constants (R), the best isotherm model fits to the dye adsorption by using copolymer is both Freundlich and Dubinin-Raduskevich isotherm models with 0.964 and 0.961 correlation constants, respectively. Both models can be used to explain dye adsorption process. All the adsorption isotherm curves can be seen in Figures 9a, b and c and constants can be seen in Table 2 .

\subsection{Adsorption kinetics}

In order to investigate the mechanism of adsorption, several kinetic models are available to describe sorption kinetics. The pseudo-second order kinetic and intra-particle diffusion models were applied to test experimental data.

The pseudo-second order kinetic model is expressed as:

$$
\frac{t}{q}=\frac{1}{k_{2} q_{e}^{2}}+\frac{t}{q_{e}}
$$

where $\mathrm{k}_{2}(\mathrm{~kg} / \mathrm{g} \cdot \mathrm{min})$ is the pseudo-second order rate constant. The linear plot of $1 / \mathrm{q}$ versus $\mathrm{t}$ gives the second-order rate constant and $\mathrm{q}_{\mathrm{e}}(\mathrm{g} / \mathrm{kg})$. This model is used to predict behavior over the whole range of adsorption and is in agreement with the chemisorption mechanism being rate-controlling step ${ }^{[25,26]}$.

In order to identify the diffusion mechanism, the intra-particle diffusion model is expressed as:

$$
\mathbf{q}=\mathbf{k p t}^{1 / 2}+\mathbf{c}
$$

Where $\mathrm{k}_{\mathrm{p}}\left(\mathrm{mg} / \mathrm{g} \cdot \mathrm{min}^{1 / 2}\right)$ is the intra-particle diffusion rate constant and c ( $\mathrm{mg} / \mathrm{g})$ is a constant which gives information about the thickness of the boundary layer. The plot of q versus $\mathrm{t}^{1 / 2}$ could yield a straight line passing through the origin if the adsorption process obeys the sole intra-particle diffusion model. The line does not pass through the origin; therefore, intra-particle diffusion is not the only rate-limiting step. It could be stated that this process is complex and involves more than one mechanism ${ }^{[14]}$.

In our study, as seen in Figures 10a and b, the pseudo-second order kinetic model fits to the adsorption process with 0.999 correlation coefficient. This supports that the rate-limiting step of dye adsorption may be chemisorption. Thus, intra-particle diffusion model $\left(\mathrm{R}^{2}=0.978\right)$ also confirms that intra-particle diffusion is not the only rate-limiting step and involves more than one mechanism because the line does not pass through the origin. The rate limiting step in our study is chemisorption mechanism. As seen in section 3.8, our adsorption occurred with ion-exchange mechanism which is also called chemisorption. The isotherm data and kinetic data comply with each other. Pseudo-second order and intra-particle diffusion kinetic models' constants were calculated and are given in Table 3.

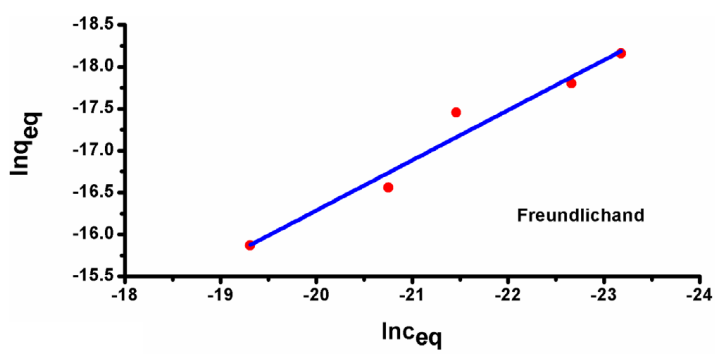

(a)

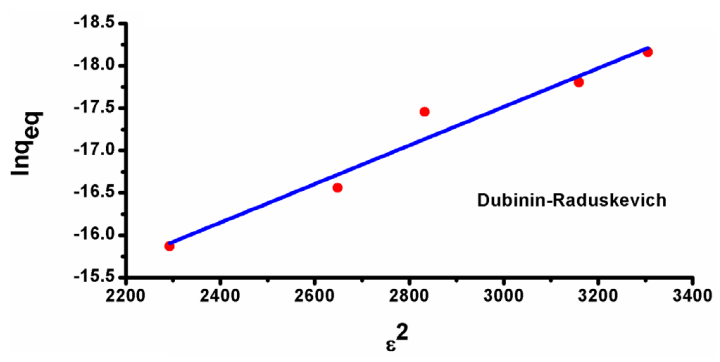

(b)

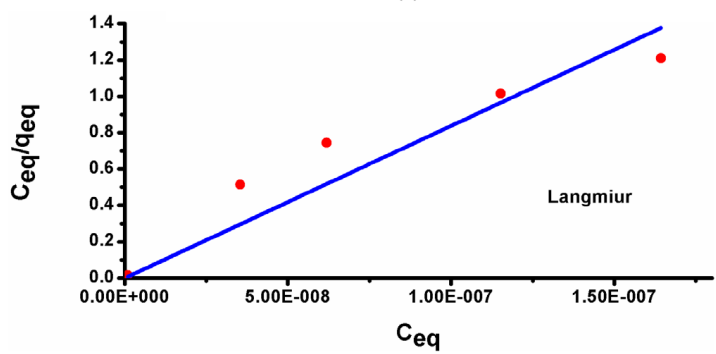

(c)

Figure 9. Freundlich isotherm (a), Dubinin-Raduskevich isotherm (b), and Langmuir isotherm (c), models.

Table 2. Langmiur, Freundlich and, Dubinin-Raduskevich isotherms constants for adsorption of Direct Brown 2.

\begin{tabular}{ccccccccccc}
\hline \multicolumn{3}{c}{ Langmiur constants } & \multicolumn{4}{c}{ Freundlich constants } & \multicolumn{5}{c}{ Dubinin-Raduskevich constants } \\
\hline $\mathbf{Q}_{\mathbf{0}}(\mathbf{m g} / \mathbf{g})$ & $\mathbf{b}(\mathbf{L} / \mathbf{m g})$ & $\mathbf{R}^{2}$ & $\mathbf{R}_{\mathbf{L}}$ & $\begin{array}{c}\mathbf{K}_{\mathbf{f}} \\
\left(\mathbf{m o l}^{1-1 / n} \mathbf{L}^{1 / n} \mathbf{g}^{-1}\right)\end{array}$ & $\mathbf{n}$ & $\mathbf{R}^{2}$ & $\mathbf{q}_{\mathbf{m}}(\mathbf{m g} / \mathbf{g})$ & $\mathbf{E}(\mathbf{k J} / \mathbf{m o l})$ & $\boldsymbol{\beta}$ & $\mathbf{R}^{2}$ \\
7 & 0.006 & 0.943 & 1 & 0.013 & 1.7 & 0.964 & 13.4 & 14.7 & -0.0023 & 0.961 \\
\hline
\end{tabular}



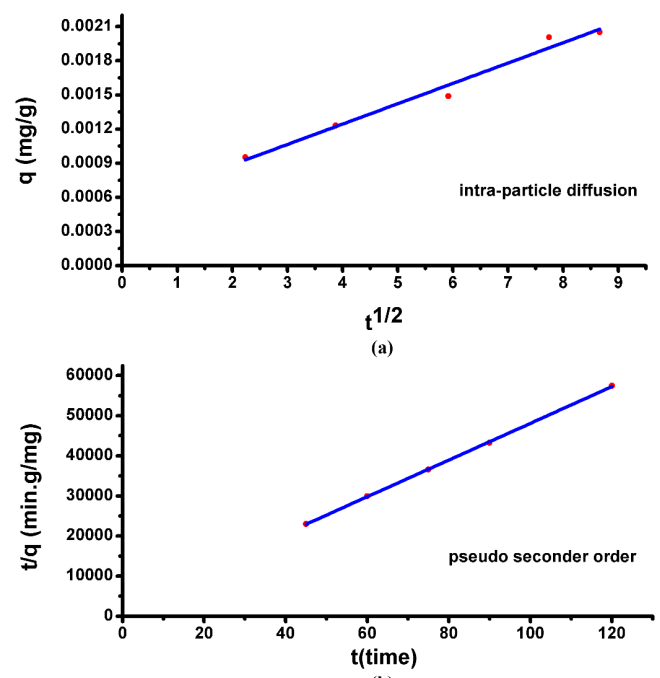

(b)

Figure 10. Pseudo second-order kinetic model (a) and Intra-particle diffusion kinetic model (b).

Table 3. Pseudo-second order and intra-particle diffusion kinetic model constants for adsorption of Direct Brown 2.

\begin{tabular}{ccc}
\hline & Pseudo-secondorder & $\begin{array}{c}\text { Intra- } \\
\text { particlediffusion }\end{array}$ \\
\hline $\mathrm{k}^{2}\left(\mathrm{~min}^{-1}\right)$ & 89.5 & - \\
$\mathrm{q}_{\mathrm{e}}(\mathrm{g} / \mathrm{kg})$ & 0.0022 & - \\
$\mathrm{c}(\mathrm{mg} / \mathrm{g})$ & - & 0.002 \\
$\mathrm{~K}_{\mathrm{p}}\left(\mathrm{mg} / \mathrm{g} \cdot \mathrm{min}^{1 / 2}\right)$ & - & 0.005 \\
$\mathrm{R}^{2}$ & 0.999 & 0.978 \\
\hline
\end{tabular}

\section{Conclusions}

In this study, we prepared Poly(AA-co-AMA) with different mole ratios by radicalic polymerization. The copolymers were used for removal of azo dye such as Direct Brown 2 from aqueous solution. The adsorption capacity was found to be highly dependent on the amount of the acrylamide, and $\mathrm{pH}$ of the solution. Adsorption capacity of poly(AA-co-AMA) copolymers was increased by increasing with amount of AA due to its positively charged $-\mathrm{NH}_{2}$ residue in given $\mathrm{pH}$. The maximum adsorption capacity is found to be $100 \%$ at $\mathrm{pH}$ 3.The kinetic studies showed that the adsorption process was consistent with the pseudo second-order kinetic model, indicating the chemical adsorption was the rate-limiting step. The adsorption of Direct Brown 2 onto Poly(AA-co-AMA) copolymer correlated well with the Freundlich and Dubinin-Raduskevich equation compared to Langmuir equation. The copolymer which released $63 \%$ of the adsorbed dye in alkaline conditions has potential for re-usage. The novelty of this study is newly synthesized copolymer (PAMA) and its potential to remove azo dyes' from wastewater.

Consequently, the copolymer can be used as an effective adsorbent for the removal of Direct Brown 2, and has potential applications in related industrial and environmental areas.

\section{References}

1. Solpan, D., \& Kolge, Z. (2006). Adsorption of Methyl Violet in aque-ous solutions by poly(N-vinylpyrrolidone-co-methacrylic acied) hydrogels. Radiation Physics and Chemistry, 75(1), 120 128. http://dx.doi.org/10.1016/j.radphyschem.2005.06.005.

2. Vivek, A. V., \& Dhamodharan, R. (2008). Amphiphilic polystyrene- graft-poly (N,N-dimethylamino-2-ethyl methacrylate) hydrogels synthesized via room temperature ATRP: Studies on swelling behaviour and dye sorption. Reactive \& Functional Polymers, 68(5), 967-973. http://dx.doi. org/10.1016/j.reactfunctpolym.2008.02.006.

3. Homayon, A. P., Marjaneh, S. Z., Simin, T., Elham, M., \& Jahanbakhsh, G. (2012). Nickel adsorption from environmental samples by ion imprinted aniline-formaldehyde polymer. Iranian Journal of Chemistry and Chemical Engineering, 31(3), 35-44. Retrieved from http://www.ijcce.ac.ir/article_5949_1204.html

4. Solpan, D., Duran, S., \& Torun, M. (2008). Removal of cationic dyes by poly(acrylamide-co-acrylic acid) hydrogels in aqueous solutions. Radiation Physics and Chemistry, 77(4), 447-452. http://dx.doi.org/10.1016/j.radphyschem.2007.08.006.

5. Lu, J. L., Wu, M. Y., Yang, X. L., Dong, Z. B., Ye, J. H., Borthakur, D., Sun, Q. L., \& Liang, Y. R. (2010). Decaffeination of tea extracts by using poly(acrylamide-co-ethylene glycol dimethylacrylate) as adsorbent. Journal of Food Engineering, 97(4), 555-562. http://dx.doi.org/10.1016/j.jfoodeng.2009.11.018.

6. Dragan, E. S., Perju, M. M., \& Dinu, M. V. (2012). Preparation and characterization of IPN composite hydrogels based on polyacrylamide and chitosan and their interaction with ionic dyes. Carbohydrate Polymers, 88(1), 270-281. http://dx.doi. org/10.1016/j.carbpol.2011.12.002.

7. Shao, D., Ren, X., Hu, J., Chen, Y., \& Wang, X. (2010). Preconcentration of $\mathrm{Pb} 2+$ from aqueous solution using poly(acrylamide) and poly(N,N-dimethylacrylamide) grafted multiwalled carbon nanotubes. Colloids and Surfaces. A, Physicochemical and Engineering Aspects, 360(1-3), 74-84. http://dx.doi.org/10.1016/j.colsurfa.2010.02.013.

8. Wang, Y., Zeng, L., Ren, X., Song, H., \& Wang, A. (2010). Removal of methyl violet from aqueous solutions using poly (acrylic acid-co-acrylamide)/attapulgite composite. Journal of Environmental Sciences, 22(1), 7-14. http://dx.doi.org/10.1016/ S1001-0742(09)60068-1. PMid:20397381

9. Işik, M., \& Sponza, D. T. (2007). Fate and toxicity of azo dye metabolites under batch long-term anaerobic incubations. Enzyme and Microbial Technology, 40(4), 934-939. http:// dx.doi.org/10.1016/j.enzmictec.2006.07.032.

10. Lučić, M., Milosavljević, N., Radetić, M., Šaponjić, Z., Radoičić, M., \& Krušić, M. K. (2014). The potential application of TiO2/ hydrogel nanocomposite for removal of various textile azo dyes. Separation and Purification Technology, 122, 206-216. http://dx.doi.org/10.1016/j.seppur.2013.11.002.

11. Sanlier, S. H., Ak, G., Yilmaz, H., Ozbakir, G., \& Cagliyan, O. (2013). Removal of textile dye, direct red 23, with glutaraldehyde cross-linked magnetic chitosan beads. Preparative Biochemistry \& Biotechnology, 43(2), 163-176. http://dx.doi.org/10.1080/ 10826068.2012.712937. PMid:23302104

12. Mittal, A., Gajbe, V., \& Mittal, J. (2008). Removal and recovery of hazardous triphenylmethane dye, Methyl Violet through adsorption over granulated waste materials. Journal of Hazardous Materials, 150(2), 364-375. http://dx.doi. org/10.1016/j.jhazmat.2007.04.117. PMid:17543448

13. Şolpan, D., Torun, M., \& Güven, O. (2008). The usability of (sodium alginate/acrylamide) semi-interpenetrating polymer networks on removal of some textile dyes. Journal of Applied Polymer Science, 108(6), 3787-3795. http://dx.doi.org/10.1002/ app. 27945 . 
14. Vardareli, T. K., Keskin, S., \& Usanmaz, A. (2008). Synthesis and Characterization of Poly(allyl methacrylate) Obtained by Free Radical Initiator. Journal of Macromolecular Science: Pure \& Applied Chemistry, 45(4), 302-311. http://dx.doi. org/10.1080/10601320701863783.

15. Zulfiqar, S., Piracha, A., \& Masud, K. (1996). The thermal degradation of poly(allyl methacrylate). Polymer Degradation \& Stability, 52(1), 89-93. http://dx.doi.org/10.1016/01413910(95)00237-5.

16. Dulman, V., \& Cucu-Man, S. M. (2009). Sorption of some textile dyes by beech wood sawdust. Journal of Hazardous Materials, 162(2-3), 1457-1464. http://dx.doi.org/10.1016/j. jhazmat.2008.06.046. PMid:18656305

17. Senthil Kumar, P., Ramalingam, S., Senthamarai, C., Niranjanaa, M., Vijayalakshmi, P., \& Sivanesan, S. (2010). Adsorption of dye from aqueous solution by cashew nut shell: Studies on equilibrium isotherm, kinetics and thermodynamics of interactions. Desalination, 261(1-2), 52-60. http://dx.doi. org/10.1016/j.desal.2010.05.032.

18. Chowdhury, S., Chakraborty, S., \& Saha, P. (2011). Biosorption of Basic Green 4 from aqueous solution by Ananas comosus (pineapple) leaf powder. Colloids and Surfaces. B, Biointerfaces, 84(2), 520-527. http://dx.doi.org/10.1016/j.colsurfb.2011.02.009. PMid:21349693

19. Mittal, A. (2006). Use of hen feathers as potential adsorbent for the removal of a hazardous dye, Brilliant Blue FCF, from wastewater. Journal of Hazardous Materials, 128(2-3), 233-239. http://dx.doi.org/10.1016/j.jhazmat.2005.08.043. PMid:16221529

20. Ofokansi, K., Winter, G., Fricker, G., \& Coester, C. (2010). Matrix-loaded biodegradable gelatin nanoparticles as new approach to improve drug loading and delivery. European Journal of Pharmaceutics and Biopharmaceutics, 76(1), 1-9. http://dx.doi.org/10.1016/j.ejpb.2010.04.008. PMid:20420904
21. Mittal, A., Gajbe, V., \& Mittal, J. (2008). Removal and recovery of hazardous triphenylmethane dye, Methyl Violet through adsorption over granulated waste materials. Journal of Hazardous Materials, 150(2), 364-375. http://dx.doi. org/10.1016/j.jhazmat.2007.04.117. PMid:17543448

22. Ngah, W. S. W., \& Fatinathan, S. (2008). Adsorption of Cu(II) ions in aqueous solution using chitosan beads, chitosan-GLA beads and chitosan-alginate beads. Chemical Engineering Journal, 143(1-3), 62-72. http://dx.doi.org/10.1016/j.cej.2007.12.006.

23. Akçay, G., Kılınç, E., \& Akçay, M. (2009). The equilibrium and kinetics studies of flurbiprofen adsorption onto tetrabutylammonium montmorillonite (TBAM). Colloids and Surfaces. A, Physicochemical and Engineering Aspects, 335(1-3), 189-193. http://dx.doi.org/10.1016/j.colsurfa.2008.11.009.

24. Rastogi, R., Gulati, N., Kotnala, R. K., Sharma, U., Jayasundar, R., \& Koul, V. (2011). Evaluation of folate conjugated pegylated thermosensitive magnetic nanocomposites for tumor imaging and therapy. Colloids and Surfaces. B, Biointerfaces, 82(1), 160-167. http://dx.doi.org/10.1016/j.colsurfb.2010.08.037. PMid:20851578

25. Chiou, M. S., Ho, P. Y., \& Li, H. Y. (2004). Adsorption of anionic dyes in acid solutions using chemically cross-linked chitosan beads. Dyes and Pigments, 60(1), 69-84. http://dx.doi. org/10.1016/S0143-7208(03)00140-2.

26. Deniz, F., \& Saygıdeğer, S. D. (2011). Removal of a hazardous azo dye (Basic Red 46) from aqueous solution by princess tree leaf. Desalination, 268(1-3), 6-11. http://dx.doi.org/10.1016/j. desal.2010.09.043.

Received: Jan. 01, 2014

Revised: June 04, 2014

Accepted: Oct. 03, 2014 